\title{
CONSIDERAÇÕES SOBRE JUSTIÇA E DIREITO NA PÓS-MODERNIDADE
}

\section{Marcus Geandré Nakano Ramiro ${ }^{1}$}

\section{RESUMO:}

O presente artigo se propõe a uma análise das possibilidades de se alcançar a justiça no mundo pós-moderno, apresentando um estudo que dá suas noções iniciais, reflete sobre o itinerário a ser seguido para tal e alguns dos dilemas que impedem sua concretização.

Palavras-chave: Justiça; Pós-modernidade; Acervo da Humanidade.

\section{CONSIDERATIONS ON JUSTICE AND LAW IN POST-MODERNITY}

\begin{abstract}
ABSCTRAT:
The present article proposes an analysis of the possibilities of achieving justice in postmodern world, presenting a study that gives its basics, reflects on the itinerary to be followed for this and some of the dilemmas that prevent its implementation.
\end{abstract}

Keywords: Justice; Postmodernity; Acquis of Humanity.

\section{INTRODUÇÃO}

O presente artigo propõe uma reflexão sobre a atual compreensão do que seja justiça e as possibilidades, ante os dilemas da pós-modernidade, de se alcançar este ideal. Para tal, propõem-se considerações iniciais sobre a noção de justiça, esclarecendo o uso dos termos e tirando eventuais ambiguidades advindas da grande força do senso comum ao tratar deste assunto, o que lhe traz grande debilidade semântica.

Após, apresenta-se uma proposta de itinerário a ser seguido para que a justiça seja uma virtude viável, discorrendo-se sobre o uso da capacidade racional, o acesso ao acervo da humanidade e o cultivo das virtudes em geral. Nesta linha de pensamento, analisa-se a justiça em face do direito positivo e o afrouxamento da valoração feita pela sociedade, gerando, de consequência um direito desvinculado da justiça e extremamente daninho para todos os seus convivas.

\footnotetext{
${ }^{1}$ Professor do Programa de Mestrado e Doutorado em Ciências Jurídicas da UniCesumar; Mestre e Doutor em Filosofia do Direito e do Estado pela Pontifícia Universidade Católica de São Paulo; bacharel em Direito e Música pela Universidade Estadual de Maringá. E-mail: marcus.geandre@ gmail.com
} 
Por fim, mesmo já sendo um tema muito discutido, afim de trazer um élan ao tema principal, discorre-se sobre a pós-modernidade e como seu modus operandi dificulta, sobremaneira, a consecução da justiça, demonstrando a necessidade de uma mudança de postura tanto individual como coletiva ante tais dilemas como primeiro passo para a sua concretização.

\section{BREVES NOÇÕES SOBRE JUSTIÇA}

O mundo do direito por muitas vezes se vê às voltas do sério perigo de deixar de lado sua cientificidade e valer-se demasiadamente do senso comum para tentar alcançar aquilo a que se propõe em profundidade e que lhe é inerente, qual seja, a consecução da justiça. Neste sentido, palavras como justiça, ética, filosofia, percorrem de tal maneira o ideário popular e verbalizam-se tão largamente nos discursos dos mais variados estilos e funcionalidades que se corre o risco de, ao iniciar um trabalho sobre quaisquer desses temas, acabar por partir de um significado que, de longe, é aquilo que é na essência. Por isso, para que se tenha uma noção correta de justiça há que percorrer os caminhos da história do direito e delimitar corretamente aquilo que se propõe estudar.

Vale-se então, no presente artigo, dos estudos de Javier Hervada (1990) sobre o tema, que aponta, de início para Roma antiga, onde era patente a preocupação de seus juristas em satisfazer a uma demanda prática diária: conseguir dar a cada homem o seu, ou seja, o que corresponderia a cada um nas diversas facetas das relações humanas: o que é o seu numa distribuição de terras, de renda, num debate, numa discussão, numa compra e venda, num relacionamento familiar, pessoal ou estatal. Àquilo que correspondia a cada um chamaram-lhe ius; à ciência que consistia em saber averiguar o ius deram o nome de ars iuris; e à virtude de conseguir constantemente mensurar o ius chamaram-lhe iustitia ou justiça.

Este conhecimento prático de saber o que é do outro, saber como há que dar, onde há que dar, quando há que dar, como há que dar, ou seja, uma parte da virtude da justiça, os romanos antigos chamaram-lhe prudência do direito ou jurisprudência (iuris prudentia). Percorrer corretamente este itinerário, praticando com primor a arte do justo é um papel dos juristas, ou seja, peritos na arte de deslindar o ius. 
Quando a vontade tem o hábito de dar a cada um o seu, ou seja, quando se verifica que há uma disposição permanente para tender a estes atos, diz-se que se possui a virtude da justiça $^{2}$ ficando claro, entretanto (e conforme Tomás de Aquino na Suma Teológica) que a justiça em si não atribui coisas, mas se guia pelo fato de que elas já estão atribuídas.

Continuando no esclarecimento destes termos principais, há que se compreender que a justiça segue-se ao direito, pressupõe o direito, ou seja, não o antecede. A justiça apresenta-se como virtude de compreender, de cumprir, de respeitar o direito e não a virtude de cria-lo. Num primeiro momento parece-se estranho tal conceito uma vez que, como alertado anteriormente, o senso comum nos leva à ideia de que a justiça é anterior ao direito, todavia há que se ter claro que todo ato de justiça pressupõe um direito constituído com anterioridade, sendo então um ato segundo. A constituição do direito é um ato de poder, não de virtude.

Desta forma, o uso da expressão "direito justo" ou "direito injusto" só encontra lugar em relação ao direito positivo, quando por um acerto ou um equívoco de quem detém o poder, o direito positivo pode atribuir ou negar a alguém o que é seu, sendo justo ou injusto. Nesta esteira de pensamento, o que preexiste ao direito positivo não é a justiça, mas o direito natural, não encarado como algo divino, mas como sendo algo atribuído por natureza à pessoa humana sem a qual ela deixaria de ser humana podendo ser alcançada pela humanidade, desde que ela se esmere e se acostume a seguir este caminho.

\section{FORMAS DE SE ALCANÇAR A JUSTIÇA}

A partir da explicação inicial sobre o que parte da filosofia do direito entende por justiça, por justo, por direito, passa-se a um ponto de relevância ainda maior dentro desta temática: como se alcançar tal comportamento justo, como se praticar adequadamente esta virtude, como conseguir compreender o que o direito nos aponta no sentido de conseguir dar a cada um o seu?

Num primeiro momento nos causa espécie a compreensão da já referida fórmula romana onde se relaciona a justiça com a virtude de se conseguir compreender o que é o seu ${ }^{3}$,

\footnotetext{
${ }^{2}$ Tomás de Aquino. Suma Teológica. II-II q. 58.

${ }^{3}$ Conforme Hans Kelsen, a fórmula se apresenta como "Suum cuique tribuere", ou seja, a cada um se deve dar o que é seu. (KELSEN, 2003. p. 18).
} 
afinal fica fácil se notar que a questão decisiva para a correta aplicação de tal fórmula não é trazida por ela, ou seja, ela pede algo que ela mesma não esclarece como alcançar. A aplicação desta fórmula pressupõe a validade de uma ordem normativa que determine previamente o que é "o seu", o que lhe é devido, de modo que se aquele que detém o poder que gera a norma for alguém deveras fraco eticamente, teremos uma norma que nos indicará equivocadamente o que é devido a cada um.

Nesta esteira, o jurista e filósofo dinamarquês Alf Ross (2003, p. 321) ironiza que “'Dar a cada um o seu’ soa esplêndido. Quem ousará questioná-lo? A única dificuldade é que esta fórmula pressupõe que eu saiba o que é devido a cada pessoa como 'o seu' (quer dizer, como seu direito). A fórmula é, assim, carente de significado visto que pressupõe a posição jurídica para a qual deveria servir de fundamento.”

A partir dessas considerações, aquela que, num primeiro momento era considerada a quintessência da justiça parece depender de outrem (justo ou não) para indicar-lhe o que é o correto. Todavia, como já observado quando se tratou das noções gerais, esse equívoco de pensamento somente encontra lugar quando ligamos essa norma (que é o próprio direito) ao direito positivo. Quando imaginamos que a virtude de conseguir dar a cada um o seu, liga-se com a excelência moral, talvez a visão se apresente de forma diversa.

No pensamento aristotélico cada ação possui uma excelência em sua realização; essa excelência seria o melhor modo de se resolver a demanda, a melhor forma de findar um litígio, a melhor maneira de sanar um problema. Essa melhor forma de comportamento não se alcança facilmente. "A prática da excelência moral é, sobretudo, um processo individual, uma prática que estabelece os limites da vida e das ações de cada pessoa. É uma atitude frente a todas as ocasiões, os desafios que a vida apresenta. É uma ação ou omissão. E apequena ou engrandece a natureza humana, dependendo da disposição do agente" (CHALITA, 2003. P. 108); não é algo perfeito, mas algo que, num dado momento histórico, valendo-se da razão, da humildade, da prática das virtudes e tendo acesso irrestrito ao acervo da humanidade, é possível de se alcançar.

Mas o próprio Aristóteles sabia dos percalços ao se palmilhar este caminho. Refletir filosoficamente acerca da justiça significa ter uma cuidadosa atitude de pensar e repensar a partir da garantia de que os indivíduos estarão interagindo numa relação de paridade entre suas intenções internas e as condições externas de sua existência, ou seja, tais reflexões passam pelo 
equilíbrio entre as propensões internas do indivíduo e os assédios externos a ele. Por isso, o trinômio, utilização da capacidade racional, prática das virtudes e acesso irrestrito ao acervo da humanidade é de extrema importância para alcançarmos a justiça.

A prática das virtudes também é estudada por Aristóteles em sua "Ética a Nicômaco", dedicando-lhe toda uma parte. Todavia, já desde a mitologia os gregos falavam sobre esse exercício como forma de se alcançar a justiça. Diferentemente de outras culturas contemporâneas a eles, os gregos tinham uma originalidade peculiar também na forma de estabelecer seu panteão. Retiravam os aspectos pavorosos e monstruosos dos deuses, humanizando a estes e divinizando os homens (CHAUí, 2005. p. 34). Deste modo, todas as mazelas e virtudes da humanidade encontravam apoio em um deus que, uma vez retratado pela mitologia traria em sua essência toda a descrição da virtude ou mazela que seu nome encerrava e, tendo um aspecto parecido com o humano, dava ensejo de que tal comportamento poderia ser alcançado por todos.

Assim se deu com a virtude da justiça, que, não obstante as diversas discussões teogônicas, é comumente representada pela figura mitológica da deusa Têmis. Filha de Urano e Gaia (céu e terra), uma mulher, sentada, com os olhos vendados, com uma espada abaixada em sua mão direita, uma balança em sua mão esquerda e com o livro da lei junto aos seus pés (KURY, 1999. p. 372). Na deusa Têmis, as características queridas pelos gregos naqueles que seriam virtuosos na justiça.

Ao estudar a mitologia, em primeiro lugar, sempre a teogonia. Sendo filha de Urano (representação do céu) e Gaia (representação da terra), a Justiça sempre terá de ter um conhecimento aprofundado sobre todas as demandas que lhe são apresentadas para julgamento, seja um julgamento formal, da cidade, seja nos julgamentos do dia a dia. Esse conhecimento, tão profundo deve ser que aparenta celeste, vir dos deuses, daqueles que sabem mais - senão tudo - sobre todas as coisas. Todavia, esse conhecimento não basta; é preciso ter os pés na terra, estar ligado à terra, conhecer suas fragilidades, seu modo de pensar e agir, suas deficiências, para apenas assim ser capaz de julgar corretamente. Desprezar esses conhecimentos, descaracteriza, pronto, a realização da justiça.

Sendo representada como uma mulher, a seu tempo, sinônimo de atenção aos detalhes, de proteção, de docilidade, de compreensão necessária para se atender, com cuidado, à demanda posta à sua frente. Não há julgamento justo com desatenção aos detalhes, às provas, às sutilezas do pleito apresentado ao julgador, gerando profundo desgosto às partes envolvidas 
quando se percebe que aquele que julga, não olhou com atenção o que foi escrito, o que foi juntado.

Unido a isso, o senso de proteção, a intenção de eliminar as hipossuficiências, já antecipando aquilo se denotará da balança em sua mão esquerda, também advém da escolha de uma figura feminina para a Justiça.

Na venda nos olhos a representação de que se deve exercitar a virtude de não deixar se levar pelas aparências, de não se iludir com o externo, de não ser superficial; faltando um sentido, aguçam-se os demais, faz-se mais perspicaz. Na espada abaixada (ou na bainha) a firme vontade de apenas usar a força como última alternativa; a necessidade de se exercitar o diálogo, da solução pacífica das controvérsias, como alegoricamente se dizia das audiências no Monte Olimpo, quando, presidindo-as, Têmis não deixava que uma voz sobrepujasse a outra, batendo sua espada no chão e fazendo dela sair um estrondo como de um forte trovão todas as vezes que isso acontecia.

$\mathrm{Na}$ balança, o exercício da equidade, tratando os iguais de maneira igual e os desiguais de maneira desigual na medida em que se desigualam (também trabalhado posteriormente por Aristóteles) não como atitude única para o comportamento justo, mas, uma somatória com todos os demais; um real exercício de conseguir enxergar os de uma mesma categoria essencial e a medida que desequilibra o tratamento entre eles.

Estando sentada, enxerga-se a autoridade querida em todos para que possam agir com justiça; o portar-se conforme se prega, o respeito pelas decisões daquele que prima seu comportamento em esforçar-se ao máximo em compreender a demanda que está à sua frente.

Por fim, a lei aos seus pés (ou abraçando-a com uma das mãos), que na visão da época, nunca seria diferente do que a expressão daquilo que é de cada um, ou seja, numa sociedade ideal, onde o povo, utilizando-se de sua capacidade racional, munido do acesso irrestrito ao acervo da humanidade, aberto à busca incessante da excelência moral estaria mais perto de compreender o ideal para cada categoria essencial do comportamento humano, assim expresso na lei.

Desta forma, para o alcance da justiça, a prática das virtudes é apenas um dos pontos a serem trabalhados e pensados de modo que, o acesso irrestrito ao acervo da humanidade a partir do uso da capacidade racional compõe o arcabouço necessário para tal meta. Eduardo Bittar 
(2005) descreve de maneira muito clara esse acervo e sua importância no contexto de uma reflexão sobre o que se está a tratar:

\begin{abstract}
A humanidade possui um acervo que merece ser protegido e cultivado. Chama-se de acervo ético da humanidade o conjunto de todas as ações, tendências, ideologias, posturas, decisões, experiências compartilhadas, normas internacionais, conquistas políticas, lições éticas, preceitos morais, máximas religiosas, ditos célebres, hábitos populares, sabedorias consagradas que, por seu valor e sua singularidade, servem de referência e espelho para as demais gerações. Patrimônio imaterial de inestimável valor, trata-se de uma somatória histórica de louváveis aspectos do comportamento humano que são capazes de dignificar a pessoa humana, oriundos de todas as civilizações e de todas as culturas. (BITTAR, 2005. P. 74)
\end{abstract}

Assim, deve se notar bem que não basta dar ou ter acesso a este acervo. A educação necessariamente deve dar condições para que o indivíduo saiba lê-lo, compreendê-lo, caso contrário seria como abrir as portas de uma grande biblioteca a um analfabeto, que poderia se deslumbrar com a beleza e grandiosidade plástica do acervo, mas não lhe seria de grande proveito intelectual tal encontro.

Além disso, importante frisar que este acesso, depois de dadas as condições para sua compreensão, deve ser irrestrito. Valendo-se de sua capacidade racional e com condições de compreendê-lo, não se poderá restringir o acesso a informações, a fatos, às alegrias e às tristezas da humanidade, independentemente do motivo; há que se ter acesso irrestrito ao acervo para que o bem seja algo possível, visto que sua consecução, necessariamente passará pelas boas escolhas que apenas acontecerão com uma real capacidade de discernimento.

Outro ponto importante é que quanto mais se visitar este acervo, quanto mais se esforçar para compreendê-lo, maiores serão as possibilidades para que a excelência venha a acontecer. Não se poderia afirmar que tudo seria resolvido com este encadeamento de ações, mas notadamente, quanto mais visitas forem feitas ao acervo, tendo em vista os demais precedentes a este encontro, maior facilidade haverá para responder às crescentes demandas advindas de um ambiente social cada vez mais complexo.

De maneira diversa, contrastando com esse acervo, existe também um conjunto de desencontros, de lamentáveis exemplos históricos que em vez de dignificar a humanidade, acaba por denegri-la, por manchar sua imagem, sua limpidez. O acesso irrestrito a tudo isso, a esse conflito, valendo-se da razão para compreendê-lo, munido das virtudes necessárias para ponderar com o devido cuidado, acompanhado da humildade de assumir que o caminho não 
está totalmente palmilhado, é o que se pode chamar de busca da excelência moral, que agora, em última análise, é o direito (como já explicado, não positivo) que indica o que é seu, em cada uma das demandas que são colocadas à nossa frente.

\section{O CUMPRIMENTO DA LEI DESVINCULADO DA NOÇÃO DE BEM}

Apesar do encadeamento lógico das ideias apresentadas, é clara a dificuldade de sua aplicação. A precariedade educacional que priva o desenvolvimento da capacidade racional, as ideologias que restringem o acesso ao acervo da humanidade e o descaso pelo pensamento filosófico que, em última análise, poderia nos levar ao exercício das virtudes necessárias para se completar o pensamento que nos conduz ao justo, podem ser alguns exemplos dessa dificuldade.

Tudo isso prejudica gravemente a compreensão do justo e a prática da justiça, gerando um aparato legiferante positivo monstruoso que nada mais é do que o retrato dessa incompreensão. Neste sentido, o direito positivo deveria cuidar apenas das minúcias para que a justiça se concretizasse, não trabalhando aspectos "macros" da vida da sociedade, sendo que, o tamanho da interferência do direito positivo nesses assuntos é inversamente proporcional ao grau de compreensão da sociedade sobre o bem que ela mesma almeja.

Mas infelizmente o que cada vez mais se apresenta é uma regulação, por parte do direito positivo, da vida dos indivíduos em sociedade em todos os seus aspectos, em detrimento duma compreensão do porquê de tantas regras que, não raras as vezes, não geram o bem esperado. Percebe-se um aparato legislativo inchado, cheio de mandamentos que garantem os interesses de poucos e, apesar de isto ser claro, uma letargia incrustrada, advinda de uma fraqueza intelectual e argumentativa, que impede a sociedade de se manifestar contra tudo isso.

Neste sentido, uma das teorias que mais prevalece quando se trata do cumprimento de regras é a que diz que a obrigatoriedade do dever-ser decorre da existência de uma sanção (LANGARO, 1996), o que, infelizmente é uma verdade. A maioria das ações que permeiam nosso cotidiano, com certeza deixariam de ser realizadas se não existisse uma sanção que nos impelisse a tal ação. Tanto isso é verdade que a sanção é chamada pela Teoria Geral do Direito como "a proteção jurídica” da relação jurídica (MONTORO, 2000. p. 465). Como já lecionava Paulo Dourado de Gusmão (2003, p. 84) "quanto mais educado for um povo, quanto mais 
civilizado e quanto mais justo for o direito, menos uso da coação física terá de fazer a autoridade pública."

Todavia, não deveria ser o castigo o mecanismo que obrigasse o cumprimento da prestação; o bem em si, sua existência e compreensão deveria constituir a obrigatoriedade do dever. O que acontece é que, numa concepção "realeana" de formação do direito positivo (baseado em sua Teoria Tridimensional), tem faltado na sociedade atual um dos aspectos principais para a sua formação: o valor, ou pelo menos, uma boa valoração.

Assim, conforme leciona Norbeto Bobbio (1995, p. 131) infelizmente "segundo o positivismo jurídico, a afirmação da validade de uma norma jurídica não implica também na afirmação de seu valor” ou seja, qualquer norma jurídica, desde que legalmente promulgada tem validade no sistema positivo, independentemente da questão de seu valor intrínseco, de sua legitimidade.

Concepções como esta foram as que permitiram a ascensão de Estados e regimes totalitários sob a simples afirmação de estarem em conformidade com a lei. Mas não precisamos ir tão longe. As leis que regulam o nosso dia a dia, a quantidade de regras sem sentido que nos obrigam a condutas por vezes ridículas, já demonstram como o valor ficou em segundo plano na aceitação daquilo que nos é imposto pelo direito:

Um direito estabelecido arbitrariamente constitui-se como tal e pode mesmo servir a alguma finalidade. E, como tal, pode gozar de império, ser reconhecido como válido e até ser efetivo. O direito, porém, como ato de poder não tem seu sentido no próprio poder. Só assim se explica a revolta, a inconformidade humana diante do arbítrio. E, aí repousa, ao mesmo tempo, a força e a fragilidade da moralidade em face do direito. É possível implantar um direito à margem ou até contra a exigência moral de justiça. Aí está a fragilidade. Todavia, é impossível evitar-lhe a manifesta percepção da injustiça e a consequente perda do sentido. Aí está a força. (FERRAZ JR, 2001. p. 354)

Conforme bem assevera Guilherme Assis de Almeida (2004, p. 45) "os valores habitam o mundo da cultura e esse é o mundo no qual o homem e a mulher estão inseridos. Consequentemente, o ato de escolha do valor mais elevado, motivador da ação e da consumação da liberdade, é diretamente influenciado pela cultura que o circunda." Por isso, o valor deve ser a luz que guia o caminho da formação do direito. Se não se consegue evitar que o direito positivo regule também as grandes demandas ideológicas, deve-se então cuidar para que, ao fazê-lo, seja feito a partir de uma correta valoração dos fatos colocados à sua frente. 


\section{AS DIFICULDADES CONTEMPORÂNEAS PARA A PRÁTICA DA JUSTIÇA}

Resta ainda debruçar estudo sobre as dificuldades contemporâneas para que a prática da justiça possa ser exercitada, analisando, mesmo que brevemente, o que tem impedido o desenvolvimento da razão (com vias do conhecimento do acervo da humanidade) e o exercício das virtudes que possam dar a sensibilidade para trilhar este caminho adequadamente.

A este período em que estamos, alguns procuram nomeá-lo como pós-modernidade, tendo em vista que a modernidade, nascida a partir da ilustração com ideais positivistas, tecnocêntricas, no progresso linear da civilização, em verdades absolutas e no planejamento racional e duradouro da ordem social e econômica dá lugar ao pós-modernismo privilegiando outras ideias.

O pós-modernismo faz opção pela contingência. E, com ela, opta pelo fragmentado, efêmero, volátil, fugaz, pelo acidental e descentrado, pelo presente sem passado e sem futuro, pelos micropoderes, microdesejos, microtextos, pelos signos sem significados, pelas imagens sem referentes, numa palavra, pela indeterminação que se torna, assim, a definição e o modo da liberdade. Esta deixa de ser a conquista da autonomia no seio da necessidade e contra a adversidade para tornar-se um jogo, figura mais alta e sublime da contingência. Mas essa definição da liberdade ainda não nos foi oferecida pelo pós-modernismo; está apenas sugerida por ele, pois definir seria cair nas armadilhas da razão, do universal, do logocentrismo falocrático ou de qualquer outro monstro que esteja em voga. (CHAUÍ, 1992. p 356).

A pós-modernidade trouxe então consigo a vontade da desconstrução da ética tradicional, uma vez que esta, sacralizada, moralista, patriarcal acreditava-se sem sentido e necessitada de uma nova roupagem.

\footnotetext{
No começo, a vinda do pluralismo (quebrando o molde da tradição, escapando ao controle apertado e meticuloso da paróquia e da comunidade local, afrouxando o domínio do monopólio ético eclesiástico) foi saudada com alegria pela minoria que pensava, debatia e escrevia. (BAUMAN, 1997. p. 29)
}

Todavia, dois problemas decorrem de tal pensamento. O primeiro é que o descrédito da ética tradicional se dá por um esquecimento de suas origens, por um comodismo das gerações em não mais ligar o seu comportamento à compreensão das ações, mas ao simples legalismo sem causa. $O$ que se quer dizer é que se se buscasse a origem de muitos dos 
comportamentos éticos tradicionais hoje repudiados, analisando-os no dado momento histórico em que se desenvolveram, geralmente haveria um sentido em sua existência.

Em segundo e, talvez mais importante, é que não obstante o apego excessivo aos cânones da ética tradicional que acabava por cegar a criticidade necessária ao desenvolvimento da humanidade, ela era o muro que protegia a mesma humanidade contra sua própria degradação. Ao romper esse muro que, verdadeiramente necessitava de uma reforma (principalmente no diz respeito à compreensão de suas regras) a sociedade atual não teve condições de reerguê-lo com novas balizas que pudessem conduzi-la à consecução de seus objetivos principais, qual seja, a dignidade de vida de seus integrantes.

A ideia de "muro" talvez não seja a mais adequada, mas o que se quer indicar é que aquilo que, mesmo que de maneira não ideal, protegia a sociedade, foi sendo descontruído e hoje, por falta de condições éticas, sociais, humanísticas, espirituais, não se consegue apresentar à humanidade um novo caminho que a leve ao bem. Talvez tivesse sido feito de maneira estrondosa, chamasse a atenção para a necessidade de mudança; entretanto, dentro de um processo desconstrutivo, a cada dia um desses tijolos foi sendo retirado, de modo que, um dia a proteção não havia mais.

A ausência de referências internas e externas, subjetivas ou sociais fez com que as pessoas absorvessem quaisquer novas propostas sem um mínimo de criticidade sobre a correção do caminho escolhido (e suas consequências), de modo que "o lugar da ética tradicional esvaziado, em função de ondas de contestação, de profunda mudança das mentalidades, de grandes revoluções técnicas, científicas e econômicas... veio a ser ocupado por desvalores" (BITTAR, 2005. p. 68) nas relações humanas, sociais e familiares, nas relações econômicas e nas relações jurídico-sociais.

Tudo isso, de um modo ou de outro sempre permeou parte da história, mas encontra-se de maneira exacerbada no período em análise. No plano das relações humanas, sociais e familiares percebe-se uma grande indiferença pelo outro e um desaparecimento do valor do culto coletivo. É nítida a relativização dos conceitos, a liberação dos instintos e apetites com a fragilização das estruturas familiares e dos relacionamentos humanos; a mulher que tanto lutou para ter seus direitos respeitados aparece agora cada vez mais com a imagem vulgarizada e reduzida - em muitos casos - a um mero instrumento de satisfação do apetite masculino. 
Em nome de uma falsa ideia de liberdade, tudo é permitido, e ao se permitir tudo, sob o impulso do imediatismo, perde-se a mesma liberdade no instante seguinte, como consequência da escravidão que a ação impensada imediatamente gera.

Nas relações econômicas também não é difícil verificar a influência do pósmodernismo. A criação de mecanismos de produção e venda em massa, a mensuração das coisas e dos produtos pelo critério econômico, a inculcação de manias, fetiches, falsas necessidades com cunho meramente comercial, o modo descartável com que os produtos são pensados e oferecidos e a exploração desenfreada das massas trabalhadoras dão uma breve visão nesta seara.

No campo jurídico-social a situação encontra-se ainda pior. A criação da mentalidade e da possibilidade da impunidade, a corrupção em todos os setores, os conluios políticos, o fisiologismo partidário, a internacionalização das estruturas criminais, os grandes muros, cercas elétricas, ambientes excludentes (condomínios, shoppings), o descrédito das instituições públicas poderiam ser apresentados como fechamento do panorama que descreve a vida pública e privada no período estudado e onde analisamos a aplicação da justiça.

Neste contexto fica difícil exigir do sujeito uma ação com um olhar mais abrangente, como "pessoa total", pois apenas o fará como portador momentâneo de um dos muitos problemas que permeiam sua vida chegando ao ponto de ficar "inconsciente" das consequências de seus atos, e como adverte Bauman (1997, p. 25) "podemos lhes fazer mal (ou elas podem nos fazer mal) inadvertidamente, por ignorância mais que de propósito, sem querer mal a quem quer que seja em particular e sem agir com maldade, e sermos, no entanto culpados moralmente. A escalada das consequências de nossas ações pode tolher-nos a imaginação moral que podemos ter. Também torna impotentes as normas éticas, poucas, mas testadas e confiáveis, que herdamos do passado ou que se nos ensinam a obedecer."

Deste modo, as dificuldades para alcançar (ou exercitar) a justiça num mundo pósmoderno quase que impedem na totalidade sua consecução, exigindo dos sujeitos uma postura individual mais marcante que, mesmo que num primeiro momento possa parecer insignificante dá início ao processo de mudança (ou quem sabe, resgate, ou reconstrução ou nova contrução) que, vencendo as inclinações pessoais do agente e as inúmeras pressões externas já pode ser considerado uma revolução mesmo que operada no pequeno espaço de sua influência. 


\section{CONCLUSÃO}

Terminado o presente trabalho percebe-se que as noções sobre o que seja justiça aparecem, não raramente, com graves problemas de compreensão, tudo isso, pela dificuldade de ligá-la ao direito natural ou ao direito positivo, o que muda totalmente a precedência no uso do termo e seu correto entendimento. Problema de igual monta é também compreender corretamente o direito natural desvinculado da origem divina, mas, unido à excelência moral alcançada pelo uso da capacidade racional e o cultivo das virtudes.

As deficiências propositais na educação, a formação humanística precária, a falta do cultivo das virtudes e a sede pelo poder, levam a humanidade a perder a capacidade de valorar corretamente os fatos que a circundam, gerando um direito positivo que, infelizmente tratando desde as questões essenciais até as mínimas ações dos indivíduos, conduz a sociedade ao sofrimento e à perda de sua própria dignidade.

Desta forma, a compreensão crítica do mundo em que vivemos, traçando um caminho de resgate dos valores que o conduzem ao bem, urge na sociedade atual, caminho este no qual a filosofia pode ajudar sobremaneira, aliada à vontade de um mundo melhor.

\section{REFERÊNCIAS}

ALMEIDA, Guilherme Assis de. Ética e direito: uma perspectiva integrada. 2 ed. São Paulo: Atlas, 2004.

ARISTÓTELES. Ética a Nicômaco. Bauru: Edipro, 2002.

BAUMAN, Zygmunt. Ética pós-moderna. Trad. João Rezende Costa. São Paulo: Paulus, 1997.

BITTAR, Eduardo C. B. Curso de ética jurídica. São Paulo: Saraiva, 2005.

BOBBIO, Norberto. O positivismo jurídico. São Paulo: Ícone, 1995.

CHALITA, Gabriel B. I. Os dez mandamentos da ética. Rio de Janeiro: Nova Fronteira, 2003.

CHAUÍ, Marilena. Convite à filosofia. São Paulo: Ática, 2005. 
1992.

Ética. São Paulo: Companhia das Letras / Secretaria Municipal de Cultura,

FERRAZ JR. Tércio Sampaio. Introdução ao estudo do direito. 3 ed. São Paulo: Atlas, 2001.

. Estudos de filosofia do direito. 3 ed. São Paulo: Atlas, 2009.

GUSMÃO, Paulo Dourado de. Introdução ao estudo do direito. 33 ed. Rio de Janeiro: Forense, 2003.

HERVADA, Javier. Crítica introdutória ao direito natural. Porto - Portugal: Resjurídica.

KELSEN, Hans. O problema da justiça. São Paulo: Martins Fontes, 2003.

O que é justiça. São Paulo: Martins Fontes, 2001.

LANGARO, Luiz Lima. Curso de deontologia jurídica. São Paulo: Saraiva, 1996.

MONTORO, André Franco. Introdução à ciência do direito. 25 ed. São Paulo: RT, 2000.

REALE, Miguel. Teoria tridimensional do direito. 5. ed. São Paulo: Saraiva, 1994.

ROSS, Alf. Direito e Justiça. Bauru: Edipro, 2003.

VILLEY, Michel. A formação do pensamento jurídico moderno. Trad. Cláudia Berliner. São Paulo: Martins Fontes, 2005. 